\title{
p-Cymene and its derivatives exhibit antiaflatoxigenic activities against Aspergillus flavus through multiple modes of action
}

\author{
Fei Tian ${ }^{1} \cdot$ So Young Woo ${ }^{1} \cdot$ Sang Yoo Lee ${ }^{1} \cdot$ \\ Hyang Sook Chun ${ }^{1}$ (D)
}

Received: 3 May 2018/Accepted: 21 June 2018/Published online: 28 June 2018

(C) The Korean Society for Applied Biological Chemistry 2018

\begin{abstract}
Three monoterpenes, 1-methyl-4-(1-methylethyl)-benzene, and its derivatives, carvacrol and thymol, were tested for their antifungal and antiaflatoxigenic activities against Aspergillus flavus, and their potential in vitro mechanisms were evaluated. The monoterpenes significantly inhibited mycelial growth, spore production, and aflatoxin production in a dose-dependent manner. Furthermore, their antifungal effects were related to the suppression of fungal development regulatory genes ( $\mathrm{brlA}$, $a b a A$, and wetA) and inhibition of ergosterol synthesis. Additionally, the down-regulation of the relative expression of genes related to aflatoxin biosynthesis ( $a f l D$, aflK, $a f Q$, and $a f(R)$ revealed an antiaflatoxigenic mechanism of the monoterpenes. These observations suggest that the three monoterpenes exhibit antiaflatoxigenic activities through multiple modes of action and may be useful for controlling aflatoxin contamination in food.
\end{abstract}

Keywords Antiaflatoxigenic · Antifungal · Carvacrol · 1-methyl-4-(1-methylethyl)-benzene · Gene expression . Membrane $\cdot$ Sporulation $\cdot$ Thymol

Electronic supplementary material The online version of this article (https://doi.org/10.1007/s13765-018-0382-4) contains supplementary material, which is available to authorized users.

Hyang Sook Chun

hschun@cau.ac.kr

1 Advanced Food Safety Research Group, BK21 Plus, School of Food Science and Technology, College of Biotechnology and Natural Resources, Chung-Ang University, Anseong 17546, Republic of Korea

\section{Introduction}

Aflatoxins are secondary metabolites produced by certain toxigenic strains of Aspergillus species and are well known for their potent toxicity, immunosuppressive activity, mutagenicity, teratogenicity, and carcinogenicity. They are classified as group 1 carcinogens by the International Agency for Research on Cancer (IARC) [1]. Contamination of agricultural products with aflatoxins poses a serious threat to human health and food security [2]. Most traditional control methods, which involve the application of synthetic chemicals, are not always successful. More importantly, the use of synthetic chemicals to control food spoilage fungi is restricted because of their long degradation period, effects on food, and side effects on humans which includes carcinogenicity, teratogenicity, and residual toxicity [3]. For example, pentachlorophenol and 2,4,6trichlorophenol have been widely used as fungicides, but their production and use are currently restricted because carcinogenicity was observed in experimental animals. Exposure to pentachlorophenol and 2,4,6-trichlorophenol was reported to be associated with an increased risk of nonHodgkin lymphoma and hepatocellular tumors, respectively, and thus were categorized as group 1 and group $2 b$ carcinogens by the IARC in 2016 [4]. Thus, alternative constituents for controlling and reducing the growth of aflatoxigenic fungi and aflatoxin production are required.

Monoterpenes, such as borneol, bornylacetate, camphor, carvacrol, 1-methyl-4-(1-methylethyl)-benzene ( $p$-cymene), eucalyptol, $\gamma$-terpinene, and thymol, are the most important constituents of extracts and essential oils of various plants and possess important antifungal and antiaflatoxigenic properties [5-7]. For example, Reddy et al. [8] reported that plant extracts from Syzygium aromaticum, 
Curcuma longa, Allium sativum, and Ocimum sanctum effectively inhibit growth and aflatoxin production of Aspergillus flavus grown in rice [8]. The extracts of Azadirachta indica and Thymus vulgaris were found to be good inhibitors of both the growth and aflatoxin production of $A$. flavus and $A$. parasiticus in vitro [9-11]. In contrast, some authors also observed stimulation of aflatoxin biosynthesis when plants extracts or essential oils were applied to aflatoxigenic fungi $[12,13]$. The mechanism of action requires detailed analysis to determine why some constituents possess strong antifungal and antiaflatoxigenic efficacies, while others do not.

$p$-Cymene is a monoterpene found in over 100 plant species such as thyme (Thymus vulgaris) and origanum (Origanum vulgare) and is used for medicinal and culinary purposes [14]. $p$-Cymene and its derivatives, carvacrol and thymol, show a range of biological activities, including antioxidant, anti-inflammatory, anxiolytic, anticancer, and antimicrobial effects [15]. While $p$-cymene, carvacrol, and thymol are the major constituents of extracts and essential oils with high antifungal and antiaflatoxigenic activities, knowledge of their mechanism of action is limited and further studies are required to before $p$-cymene, carvacrol, and thymol can be recommended as promising candidates to fight Aspergillus app. and aflatoxin contamination.

The main objective of this study was to characterize the in vitro antiaflatoxigenic activities of $p$-cymene and its derivatives, carvacrol and thymol, on A. flavus and explore their mechanism of action by determining the effects on (1) fungal growth, (2) sporulation, (3) fungal membrane, (4) aflatoxin production, and (5) expression of related genes.

\section{Materials and methods}

\section{Microorganism and culture conditions}

Aspergillus flavus KCCM 60330 was obtained from the Korea Culture Center of Microorganisms (KCCM, Seoul, Korea). All cultures were grown on potato dextrose agar medium (PDA, BD Difco ${ }^{\mathrm{TM}}$, Detroit, MI, USA) in a thermostatic incubator (Sejong Scientific Co., Gyeonggido, Korea) at $28{ }^{\circ} \mathrm{C}$ in the dark.

\section{Reagents and standards}

p-Cymene, carvacrol, and thymol were purchased from Sigma-Aldrich (St. Louis, MO, USA). All monoterpenes were diluted with dimethylsulfoxide to a final concentration of $500 \mathrm{mg} / \mathrm{L}$ and stored at $4{ }^{\circ} \mathrm{C}$ until use.

Standards of aflatoxins were purchased from SigmaAldrich and prepared according to the manual of official methods of analysis [16]. All reagents, fine chemicals, and solvents for high-performance liquid chromatography (HPLC) were purchased from Honeywell Burdick \& Jackson (Muskegon, MI, USA).

\section{Determination of fungal radial growth}

To determine the effects of the three monoterpenes on the radial growth of $A$. flavus, PDA was prepared by adding $p$ cymene, carvacrol, and thymol $(20,40$, and $80 \mathrm{mg} / \mathrm{L})$ to the medium before solidification. PDA without the three monoterpenes was used as a control medium. Each medium was inoculated with $20 \mu \mathrm{L}$ of conidia suspension and incubated at $28{ }^{\circ} \mathrm{C}$ in the dark for 7 days. Colony growth diameter was measured after incubation. All treatments were replicated three times. Growth inhibition of treatment against the control was calculated as a percentage using the following formula:

Inhibition rate $(\%)=(C-T) / C$

where $C$ is an average of hyphal extension ( $\mathrm{mm}$ ) in the control and $T$ is an average of hyphal extension $(\mathrm{mm})$ of plates treated with an individual monoterpene.

\section{Determination of fungal spore production}

To evaluate spore production, 3 agar plugs $(8 \mathrm{~mm}$ in diameter) were taken from each PDA plate and added to $10 \mathrm{~mL}$ of sterile saline solution. The solution was mixed for 10 min using a vortex mixer and then diluted several times, after which the spores were counted using a hemocytometer.

\section{Inspection of fungal conidial head}

After incubation, mycelia of A. flavus KCCM 60330 were collected from the control and test groups for microscopic observation. All samples were fixed in $95 \%(\mathrm{v} / \mathrm{v})$ ethanol for $30 \mathrm{~min}$. The mycelia samples were washed and resuspended in phosphate-buffered saline $(\mathrm{pH} 7.5)$. The fungal conidial head was visualized and photographed with a microscope (Nikon, Inc., Tokyo, Japan).

\section{Determination of ergosterol content}

Fungal mycelia harvested from each group were washed twice with distilled water and dried at $60{ }^{\circ} \mathrm{C}$ for $3 \mathrm{~h}$. One hundred milligrams of dry mycelia were ground into a powder, mixed with $8 \mathrm{~mL}$ of $3 \mathrm{M} \mathrm{KOH}$ (in ethanol), and incubated at $80{ }^{\circ} \mathrm{C}$ on a shaker in a water bath for $4 \mathrm{~h}$. The solutions were then centrifuged for $15 \mathrm{~min}$ at $4000 \mathrm{rpm}$, and the supernatants were transferred into new tubes and diluted with $2 \mathrm{~mL}$ of distilled water. Ergosterol was then extracted from the solutions by two successive applications 
of $5 \mathrm{~mL} n$-hexane. The organic fractions were evaporated under $\mathrm{N} 2$ gas and resuspended in $1 \mathrm{~mL}$ of methanol. The concentration of ergosterol was determined with HPLC using an Agilent 1200 LC system (Agilent Technologies, Santa Clara, CA, USA). The ergosterol in the injected $100 \mu \mathrm{L}$ samples was separated with a reversed phase $\mathrm{C} 18$ column $(250 \mathrm{~mm} \times 4.6 \mathrm{~mm}, 5 \mu \mathrm{m}$; Waters, Milford, MA, USA) using $100 \%$ methanol as mobile phase. The mobile phase was pumped at a constant flow rate of $1.5 \mathrm{~mL} / \mathrm{min}$ for $20 \mathrm{~min}$. The retention time of ergosterol was approximately $11.18 \mathrm{~min}$. The amount of ergosterol was quantified using a UV detector (at $280 \mathrm{~nm}$ ). Ergosterol concentration was calculated based on a standard calibration curve. The organic fractions were evaporated under nitrogen, resuspended in $1 \mathrm{~mL}$ of methanol, and tested with a HPLC system with UV detection at $280 \mathrm{~nm}$. The ergosterol biosynthesis inhibition rate was calculated using the following equation:

Inhibition rate $(\%)=(E c-E t) / E c$

where $E c$ is the average mycelial ergosterol content $(\mathrm{mg} /$ $\mathrm{mg}$ mycelium) in the control and $E t$ is the average mycelia ergosterol content ( $\mathrm{mg} / \mathrm{mg}$ mycelium) in samples treated with an individual monoterpene.

\section{Aflatoxin production analysis}

Aflatoxin B1 was determined as described previously [17] with minor modifications. For aflatoxin extraction, 3 agar plugs were collected from each PDA plate and added to test tubes. Aflatoxins were extracted three times with $1 \mathrm{~mL}$ methanol and isolated with an immunoaffinity column (VICAM, Nixa, MO, USA) according to the manufacturer's instructions. The eluate was directly purged using $\mathrm{N}_{2}$ gas, and the dried residue was redissolved in $1 \mathrm{~mL}$ of a mixture of $0.1 \%$ acetic acid/acetonitrile/methyl alcohol (59:14:29, v/v/v, mobile phase). The solution was filtered through a $0.2 \mu \mathrm{m}$ syringe filter and stored at $-20{ }^{\circ} \mathrm{C}$ before analysis. HPLC analysis was performed using an Agilent 1200 LC system (Agilent Technologies, Santa Clara, CA, USA). The aflatoxin B1 in the injected $50 \mu \mathrm{L}$ samples was separated with a reversed phase C18 column (150 mm × $4.6 \mathrm{~mm}, 3.5 \mu \mathrm{m}$; Waters, Milford, MA, USA). The mobile phase was pumped at a constant flow rate of $0.5 \mathrm{~mL} / \mathrm{min}$ for $20 \mathrm{~min}$. The retention time of aflatoxin B1 was approximately $10.92 \mathrm{~min}$. The amount of aflatoxin B1 was quantified using a fluorescence detector (excitation at $360 \mathrm{~nm}$ and emission at $440 \mathrm{~nm}$ ). Aflatoxin B1 concentration was calculated based on a standard calibration curve. The aflatoxin production inhibition rate was calculated using the following equation:

Inhibition rate $(\%)=(A c-A t) / A c$ where $A c$ is the average aflatoxin $\mathrm{B} 1$ content in the control and $A t$ is the average aflatoxin B1 content in samples treated with an individual monoterpene.

\section{Gene expression analysis}

Fungal mycelia on the PDA medium were harvested and placed in a mortar and ground to a fine powder with an appropriate amount of liquid nitrogen. Total RNA was extracted from the mycelia using QIAzol Lysis reagent (Qiagen, Hilden, Germany). The RNA extracts were quantified by determining the absorbance at both 260 and $280 \mathrm{~nm}$ using a $\mu$ Drop plate system (Thermo Fisher Scientific, Inc., Waltham, MA, USA), and RNA was then evaluated qualitatively by agarose gel electrophoresis $(1 \%$, $\mathrm{v} / \mathrm{w})$ with ethidium bromide. cDNA was prepared using a Maxima first strand cDNA synthesis kit (Thermo Fisher Scientific, Inc.). A Rotor-Gene SYBR Green PCR Kit (Qiagen) was used for real-time PCR analysis.

Specific primers synthesized by Genotech (Daejeon, Korea) were used in this study to test the effects of the three monoterpenes (Table 1). Amplification was performed as follows: denaturation at $95^{\circ} \mathrm{C}$ for $30 \mathrm{~s}$, annealing at $60{ }^{\circ} \mathrm{C}$ for $20 \mathrm{~s}$, and elongation at $72{ }^{\circ} \mathrm{C}$ for

Table 1 List of qRT-PCR primers

\begin{tabular}{|c|c|}
\hline Target genes & Sequences \\
\hline \multicolumn{2}{|c|}{ Conidial head development regulation } \\
\hline brlA & $\begin{array}{l}\text { F: 5'-GATCTCACCTCGAGCGAAAC-3' } \\
\text { R: 5'-ATAGTCTGGGAGGGGCATCT-3' }\end{array}$ \\
\hline$a b a A$ & $\begin{array}{l}\text { F: 5'-ATCTGCAGGTCCTCGACTCT-3' } \\
\text { R: } 5^{\prime} \text {-TCGTTCTAATGCTGGCTCAC-3' }\end{array}$ \\
\hline wetA & $\begin{array}{l}\text { F: 5'-TCGTTCTAATGCTGGCTCAC-3' } \\
\text { R: 5'-TCGTTCTAATGCTGGCTCAC-3' }\end{array}$ \\
\hline \multicolumn{2}{|c|}{ Aflatoxin production } \\
\hline$a f D$ & $\begin{array}{l}\text { F: } 5^{\prime} \text {-TCCAGGCACACATGATGGTC-3' } \\
\text { R: } 5^{\prime} \text {-TGTGGATAACGAAGTGCCCC-3' }\end{array}$ \\
\hline aflK & $\begin{array}{l}\text { F: 5'-GAACTGCTTCAGTTGCCGTG-3' } \\
\text { R: } 5^{\prime} \text {-ACGAGGGTTCGTTTCTGGAC-3' }\end{array}$ \\
\hline aflQ & $\begin{array}{l}\text { F: 5'-TTAAGGCAGCGGAATACAAG-3' } \\
\text { R: 5'-GACGCCCAAAGCCGAACACAAA-3' }\end{array}$ \\
\hline aflR & $\begin{array}{l}\text { F: 5'-GCACCCTGTCTTCCCTAACA-3' } \\
\text { R: } 5^{\prime} \text {-ACGACCATGCTCAGCAAGTA-3' }\end{array}$ \\
\hline \multicolumn{2}{|c|}{ Ergosterol biosynthesis } \\
\hline $\operatorname{erg} 28$ & $\begin{array}{l}\text { F: 5'-TTGCCTCCTTTTGAGGGCTT-3' } \\
\text { R: 5'-CACAGGGGTCGTGATGTTGT-3' }\end{array}$ \\
\hline \multicolumn{2}{|c|}{ Internal standard } \\
\hline$\beta$-tubulin & $\begin{array}{l}\text { F: 5'-TCCAAGGTTTCCAGATCACC-3' } \\
\text { R: 5'-GAACTCCTCACGGATCTTGG-3' }\end{array}$ \\
\hline
\end{tabular}


$30 \mathrm{~s}$. Forty rounds of amplification were conducted according to the thermal cycling procedure with a postcycling step at $95{ }^{\circ} \mathrm{C}$ for $5 \mathrm{~min}$. Real-time PCR was performed three times for each sample in a CFX96 system (Bio-Rad, Hercules, CA, USA). Differences in gene expression were calculated using the $\Delta \mathrm{C} t$ method.

\section{Statistical analysis}

Experiments were performed three times, and the data were expressed as the mean \pm standard deviation (SD). Statistically significant differences between experimental groups were determined by one-way analysis of variance with Duncan's multiple range test. Differences between experimental groups were considered significant at $p<0.05$. Statistical analyses were performed using SPSS Version 19 (SPSS, Inc., Chicago, IL, USA).

\section{Results}

\section{Effect of three monoterpenes on growth of $\boldsymbol{A}$. flavus}

p-Cymene, thymol, and carvacrol effectively inhibited the growth of A. flavus in a concentration-dependent manner (Table 2). All three tested monoterpenes completely blocked the growth of A. flavus at a concentration of $80 \mathrm{mg} / \mathrm{L}$. Thymol and carvacrol showed slightly stronger inhibition activities than $p$-cymene. Notably, the observed decrease in fungal growth was accompanied by a loss of mycelial pigmentation (Fig. S1).

\section{Effect of three monoterpenes on sporulation of $A$. flavus}

The three monoterpenes showed different levels of inhibition of sporulation of A flavus. Thymol exhibited the highest inhibition rate $(32 \%$ at $20 \mathrm{mg} / \mathrm{L}$ and $67 \%$ at $40 \mathrm{mg} /$ $\mathrm{L})$, followed by carvacrol $(46 \%$ at $20 \mathrm{mg} / \mathrm{L}$ and $59 \%$ at $40 \mathrm{mg} / \mathrm{L})$. $p$-Cymene did not significantly inhibit spore production (Fig. 1).

Microscopic observation revealed that thymol had the most marked effects on the morphology of the fungal conidial head. Upon thymol treatment, decreased conidial head size and lack of sporulation were observed (Fig. 2D). Treatment with A. flavus with carvacrol had a similar effect (Fig. 2C). However, treatment with $p$-cymene resulted in no obvious morphological difference or changes in sporulation compared to in the control (Fig. 2B).

Figure 3 shows the results of qRT-PCR experiments for brlA, abaA, and wetA in A. flavus. Compared to the control, all three genes were downregulated following treatment with the three monoterpenes. Carvacrol treatment resulted in the most significant inhibition, followed by $p$-cymene, and thymol treatment. These results suggest that the three tested monoterpenes affect the regulation of fungal development at the transcription level.

Table 2 Effect of $p$-cymene, carvacrol, and thymol on growth and aflatoxin B1 production by Aspergillus flavus

\begin{tabular}{|c|c|c|c|c|c|}
\hline \multirow[t]{2}{*}{ Monoterpenes } & \multirow[t]{2}{*}{ Concentration $(\mathrm{mg} / \mathrm{L})$} & \multicolumn{2}{|l|}{ Fungal growth } & \multicolumn{2}{|c|}{ Aflatoxin B1 production ${ }^{2}$} \\
\hline & & Colony diameter $(\mathrm{mm})^{1}$ & Inhibition (\%) & Aflatoxin B1 (ng) $)^{1}$ & Inhibition $(\%)$ \\
\hline \multirow[t]{4}{*}{$p$-Cymene } & 0 & $83.5 \pm 0.5^{\mathrm{a}}$ & - & $860.75 \pm 3.05^{\mathrm{a}}$ & - \\
\hline & 20 & $57.2 \pm 4.6^{\mathrm{b}}$ & $31.5 \pm 5.5$ & $1.93 \pm 0.25^{\mathrm{b}}$ & $99.8 \pm 0.03$ \\
\hline & 40 & $41.2 \pm 1.8^{\mathrm{c}}$ & $50.7 \pm 2.1$ & $0.96 \pm 0.12^{\mathrm{c}}$ & $99.9 \pm 0.01$ \\
\hline & 80 & ND & 100 & ND & 100 \\
\hline \multirow[t]{4}{*}{ Carvacrol } & 0 & $83.5 \pm 0.5^{\mathrm{a}}$ & - & $860.75 \pm 3.05^{\mathrm{a}}$ & - \\
\hline & 20 & $53.6 \pm 2.3^{\mathrm{b}}$ & $35.8 \pm 2.7$ & $22.85 \pm 2.31^{\mathrm{b}}$ & $97.4 \pm 0.27$ \\
\hline & 40 & $29.7 \pm 3.4^{\mathrm{c}}$ & $64.4 \pm 4.1$ & $1.03 \pm 0.37^{\mathrm{c}}$ & $99.9 \pm 0.04$ \\
\hline & 80 & ND & 100 & ND & 100 \\
\hline \multirow[t]{4}{*}{ Thymol } & 0 & $83.5 \pm 0.5^{\mathrm{a}}$ & - & $860.75 \pm 3.05^{\mathrm{a}}$ & - \\
\hline & 20 & $53.6 \pm 2.3^{\mathrm{b}}$ & $35.8 \pm 2.7$ & $242.67 \pm 23.75^{\mathrm{b}}$ & $71.8 \pm 2.76$ \\
\hline & 40 & $30.9 \pm 2.3^{\mathrm{c}}$ & $63.0 \pm 2.7$ & $15.89 \pm 0.68^{\mathrm{c}}$ & $98.2 \pm 0.08$ \\
\hline & 80 & ND & 100 & ND & 100 \\
\hline
\end{tabular}

${ }^{1}$ Values given are mean \pm SD of three separate experiments. Values followed by different letters are significantly different according to Duncan's multiple range test at $p<0.05$

${ }^{2}$ Aflatoxin B1 production was represented by the aflatoxin B1 quantity in three agar plus taken from each group as described in section Materials and methods 


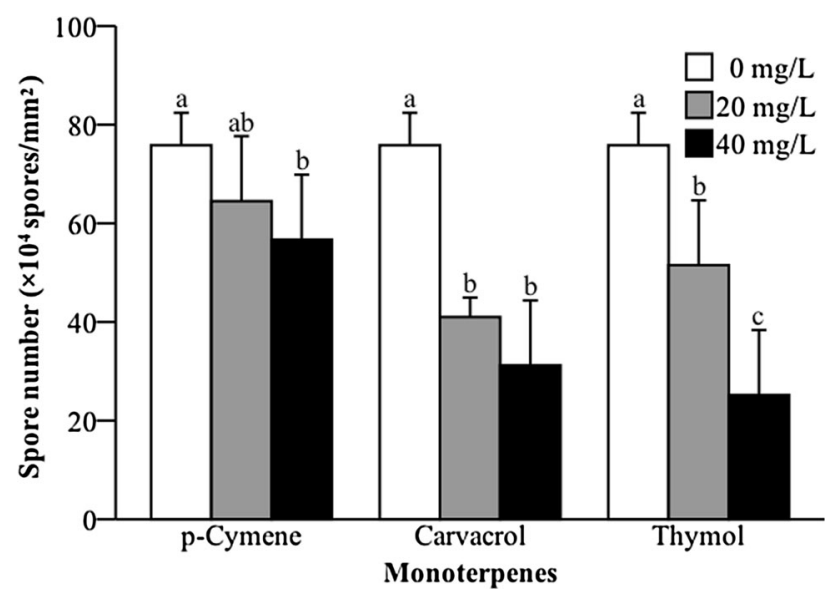

Fig. 1 Effect of $p$-cymene, carvacrol, and thymol on sporulation of A. flavus. Fungal colonies were cultured at $28{ }^{\circ} \mathrm{C}$ in the dark for 7 days on PDA medium supplemented with 0 (control), 20, and $40 \mathrm{mg} / \mathrm{L}$ of $p$-cymene, carvacrol, and thymol. Bars represented standard deviations of the means. Values followed by different letters are significantly different according to Duncan's multiple range test at $p<0.05$

\section{Effect of three monoterpenes on ergosterol biosynthesis}

Ergosterol levels were dose-dependently decreased in fungal cells after treatment with the three monoterpenes at 0,20 , and $40 \mathrm{mg} / \mathrm{L}$ (Table 3). p-Cymene and carvacrol exhibited stronger inhibition against ergosterol production than did thymol.

qRT-PCR analysis of erg28, an essential biosynthesis gene for ergosterol production, showed that both carvacrol and $p$-cymene effectively interfered with the ergosterol biosynthesis pathway. Thymol showed no obvious effects at the lower concentration (20 mg/L) (Fig. 4).

\section{Effect of three monoterpenes on aflatoxin $B_{1}$ production by A. flavus}

Table 2 shows the effect of the three monoterpenes on aflatoxin $\mathrm{B}_{1}$ production. There was a significant decrease in aflatoxin production by $A$. flavus treated with the tested monoterpenes. Treating A. flavus with monoterpenes resulted in great reductions in aflatoxin $\mathrm{B}_{1}$ production. At $20 \mathrm{mg} / \mathrm{L}, \quad p$-cymene, carvacrol, and thymol decreased aflatoxin production by 99.8, 97.4, and $71.8 \%$, while decreasing fungal growth by $31.5,35.8$, and $35.8 \%$, respectively. Upon treatment at $40 \mathrm{mg} / \mathrm{L}$, aflatoxin production was reduced by $99.9,98.2$, and $99.9 \%$ and fungal growth reduced by 50.7, 63.0, and 64.4\%, respectively.

Figure 5 shows the changes in aflD, aflK, aflQ, and $a f R$ mRNA expression by A. flavus upon treatment with the three monoterpenes. Treatment with $p$-cymene and carvacrol significantly affected aflatoxin $B_{1}$ production, similar to treatment with thymol at a higher concentration (40 mg/L). However, expression of aflatoxin productionrelated genes was not affected by treatment with thymol at a lower concentration $(20 \mathrm{mg} / \mathrm{L})$. Unexpectedly, the levels of these mRNAs were significantly increased.

\section{Discussion}

Monoterpenes from different plants or their essential oils have always been of great interest to researchers because of their potential to inhibit pathogens and their bioactivities [18]. The antimicrobial properties of a few monoterpenes have been reported, but their mechanisms of action are not well understood [18, 19].

The results of the fungal radial growth experiments suggested that $p$-cymene and its derivatives, carvacrol and thymol, exhibited extensive antifungal activity against $A$. flavus. Both thymol and carvacrol significantly inhibited conidial production and hyphal growth of A. flavus. However, $p$-cymene inhibited fungal growth but did not affect spore production. This effect was confirmed by microscopy inspection, which indicated that the size and shape of the $A$. flavus conidial head was not affected by $p$-cymene treatment. This disparity suggests a different mode of action among $p$-cymene and its derivatives, carvacrol and thymol.

Treatment with $p$-cymene and its derivatives, carvacrol and thymol, caused a significant loss in A. flavus colony pigmentation. This suggests that these three monoterpenes block the biosynthesis of fungal melanins, a high-molecular weight hydrophobic pigment synthesized via the polyketide synthase-dependent pathway [20, 21], in $A$. flavus fungal cells. It has been suggested that blocking melanin biosynthesis in pathogenic fungi can decrease their pathogenicity and increase their sensibility to various biotic and abiotic stresses [22, 23]. Aflatoxins are produced also via the polyketide synthase pathway. The first stable intermediate in the aflatoxin biosynthesis pathway, norsolorinic acid, has a very similar structure to the pigments of $A$. flavus spores [24], suggesting that the aflatoxin and melanin biosynthetic pathways have common initial stages.

As the major sterol constituent in the fungal membrane, ergosterol plays an important role in maintaining the integrity and function of the plasma membrane and localization of membrane proteins [25]. Therefore, ergosterol has been used as a classical drug target to combat fungal infection. In this study, our results showed that treatment with $p$-cymene and its derivatives, carvacrol and thymol, significantly decreased the ergosterol content in A. flavus. Similar results were reported for other fungal species [26]. The down-regulation of erg28 expression induced by the tested monoterpenes suggests that they disrupt ergosterol biosynthesis at the gene expression level. 

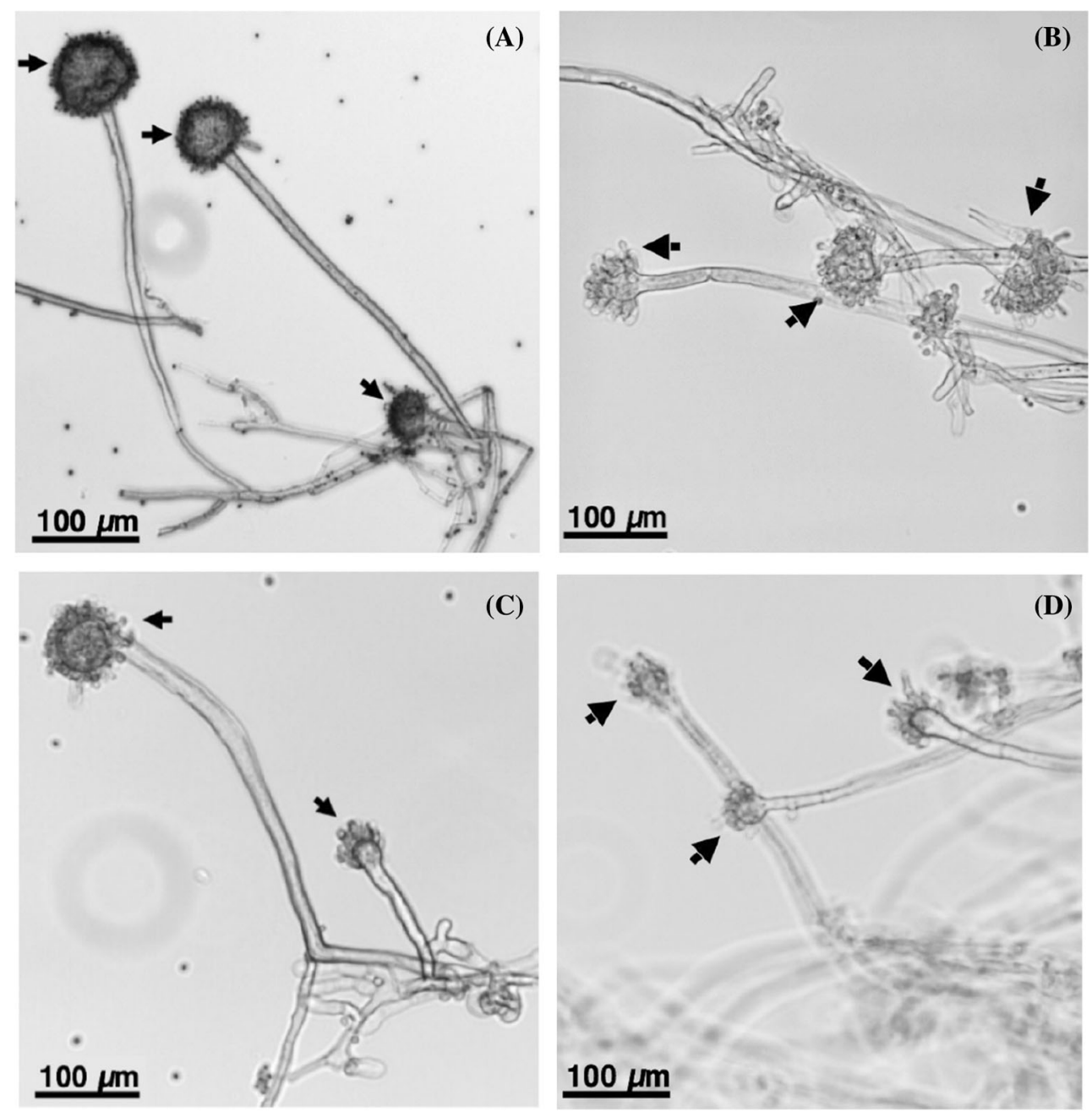

Fig. 2 Microscopic inspection of A. flavus conidial head. Conidial heads were taken from fungal colony cultured on PDA (A) and PDA supplemented with (B) p-cymene, (C) carvacrol, and (D) thymol

All three tested monoterpenes exhibited much higher activity against aflatoxin production than against fungal growth, suggesting that the antiaflatoxigenic activity of $p$ cymene and its derivatives, carvacrol and thymol, is not a secondary effect of fungal growth inhibition. $p$-Cymene had the weakest effect on fungal growth; however, its inhibition of aflatoxin production was the strongest among the three monoterpenes. Carvacrol showed higher antiaflatoxigenic activity than thymol at the same concentration, although a similar growth inhibition rate was observed. The tested monoterpenes inhibited both aflatoxin production and conidia production of A. flavus. It has been suggested that there is a relationship between conidiation and aflatoxin production in Aspergillus spp. [27]. Many conidiation-inhibiting constituents also inhibit aflatoxin production. For example, Yoshinari et al. [28] found that dioctatin $\mathrm{A}$ and 1,4-diamino-2-butanone inhibit aflatoxin production and conidiation of $A$. parasiticus. The effects of $p$-cymene, carvacrol, and thymol on the key regulatory $(a f R)$ and structural genes ( $a f D$, aflK, and $a f Q$ ) involved in aflatoxin production were also analyzed. The results suggested that the tested monoterpenes strongly inhibited the expression of genes related to aflatoxin biosynthesis. Because $p$-cymene, carvacrol, and thymol reduced both the mRNA levels of aflatoxin biosynthesis genes and fungal development regulatory genes ( $b r l A, a b a A$, and wetA), they may affect a regulatory system that controls both aflatoxin production and conidiation.

This study demonstrated that three monoterpenes, $p$ cymene, carvacrol, and thymol, have antifungal and 

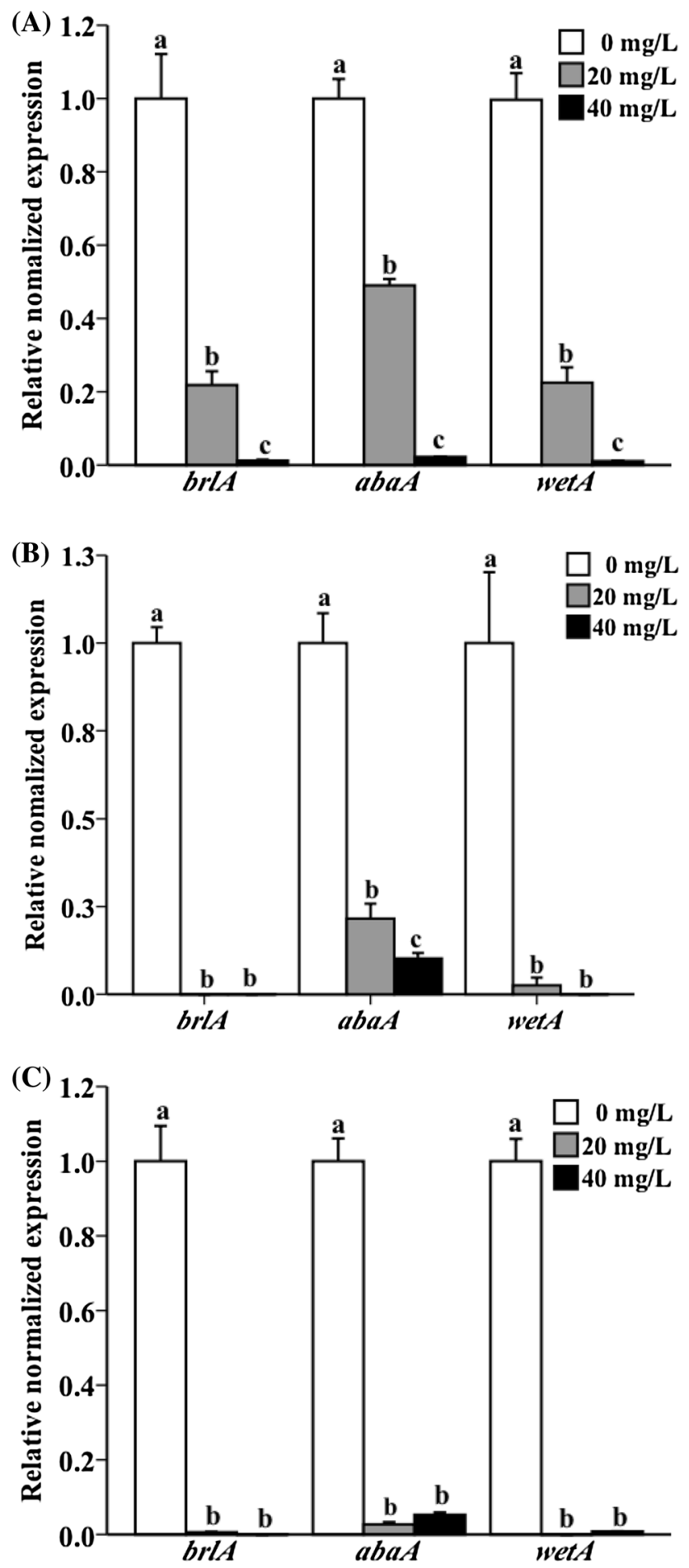

Fig. 3 Quantitative real-time polymerase chain reaction (qRT-PCR) analysis of the expression of brlA, abaA, and wetA in A. flavus growth under (A) p-cymene, (B) carvacrol, and (C) thymol treatment. Bars represented standard deviations of the means. Values followed by different letters are significantly different according to Duncan's multiple range test at $p<0.05$
Table 3 Effect of $p$-cymene, carvacrol, and thymol on ergosterol content of mycelia of $A$. flavus

\begin{tabular}{lcl}
\hline Compounds & Concentration $(\mathrm{mg} / \mathrm{L})$ & Ergosterol content $(\mathrm{mg} / \mathrm{g})^{1}$ \\
\hline Control & 0 & $3.99 \pm 0.03^{\mathrm{a}}$ \\
p-Cymene & 20 & $3.22 \pm 0.06^{\mathrm{b}}$ \\
& 40 & $2.37 \pm 0.05^{\mathrm{f}}$ \\
Thymol & 20 & $3.27 \pm 0.07^{\mathrm{b}}$ \\
& 40 & $2.75 \pm 0.01^{\mathrm{d}}$ \\
Carvacrol & 20 & $3.05 \pm 0.07^{\mathrm{c}}$ \\
& 40 & $2.58 \pm 0.24^{\mathrm{e}}$
\end{tabular}

${ }^{1}$ Values given are mean \pm SD of three separate experiments. Values followed by different letters are significantly different according to Duncan's multiple range test at $p<0.05$

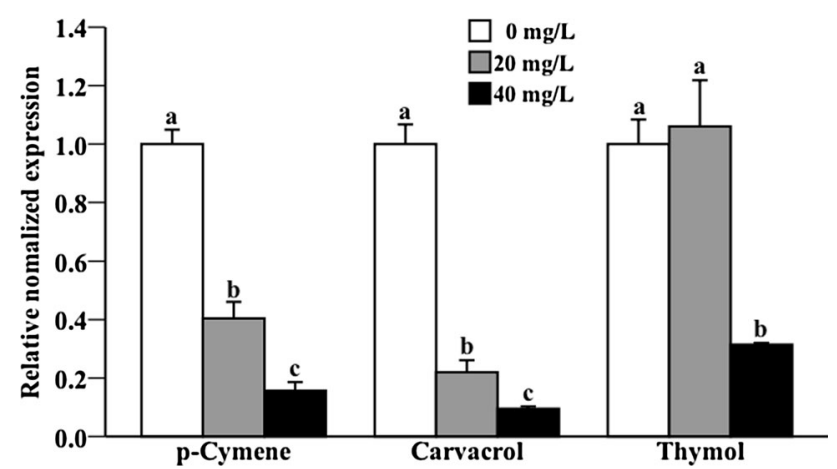

Fig. 4 Relative expression levels of the gene ( $\operatorname{erg} 28)$ responsible for ergosterol biosynthesis in fungal cells growth on a medium supplemented with $p$-cymene, carvacrol, and thymol. Bars represent standard deviations of the means. Values followed by different letters are significantly different according to Duncan's multiple range test at $p<0.05$

antiaflatoxigenic activities through multiple modes of action. Their activities may be attributed to their ability to (1) inhibit conidia production by interrupting fungal development regulatory factors; (2) cause cell membrane function disruption by inhibiting ergosterol biosynthesis, and (3) block the transcription of regulatory and structural genes involved in aflatoxin production. Additionally, because the three monoterpenes used in this study have been listed by the U.S. FDA as "Generally Recognized as Safe (GRAS)" substances, they also hold potential for application against Aspergillus app. and aflatoxin contamination in food. 

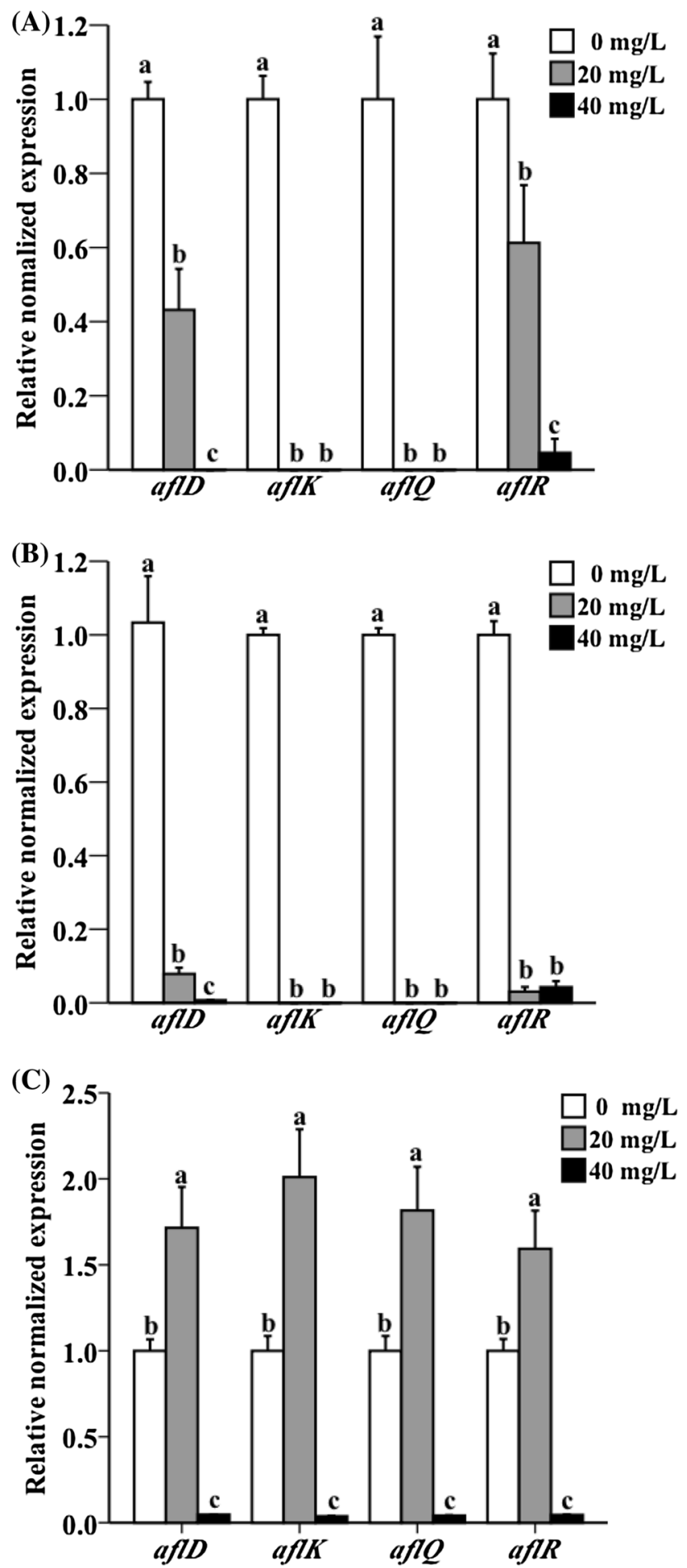

Fig. 5 Relative expression levels of genes (aflD, aflK, aflQ, aflR) responsible for aflatoxin biosynthesis in fungal cells growth on medium supplemented with (A) p-cymene, (B) carvacrol, and (C) thymol. Bars represent standard deviations of the means. Values followed by different letters are significantly different according to Duncan's multiple range test at $p<0.05$

Acknowledgments This work was supported by the Bio-Synergy Research Project (NRF-2013M3A9C4078156) of the Ministry of Science, the Chung-Ang University Graduate Research Scholarship,
Chung-Ang University Young Scientist Scholarship (CAYSS), and BK21 Plus (Brain Korea 21 Program for Leading Universities \& Students) Scholarship, Republic of Korea.

\section{References}

1. IARC (1993) Some naturally occurring substances: food items and constituents, heterocyclic aromatic amines and mycotoxins. IARC Monogr Eval Carcinog Risk Chem Hum 56:245-521

2. Williams JH, Phillips TD, Jolly PE, Stiles JK, Jolly CM, Aggarwal D (2004) Human aflatoxicosis in developing countries: a review of toxicology, exposure, potential health consequences, and interventions. Am J Clin Nutr 80:1106-1122

3. Tripathi P, Dubey NK (2004) Exploitation of natural products as an alternative strategy to control postharvest fungal rotting of fruit and vegetables. Postharvest Biol Technol 32:235-245

4. Guyton KZ, Loomis D, Grosse Y, El Ghissassi F, Bouvard V, Benbrahim-Tallaa L, Guha N, Mattock H, Straif K (2016) Carcinogenicity of pentachlorophenol and some related compounds. Lancet Oncol 12:1637-1638

5. Paranagama PA, Abeysekera KHT, Abeywickrama K, Nugaliyadde L (2003) Fungicidal and anti-aflatoxigenic effects of essential oil of Cymbopogon citratus (DC.) Stapf. (lemon grass) against Aspergillus flavus Link. isolated from stored rice. Lett Appl Microbiol 37:86-90

6. Lis-Balchin M, Deans SG, Eaglesham E (1998) Relationship between bioactivity and chemical composition of commercial essential oils. Flavour Frag J 13:98-104

7. Rojas-Graü MA, Avena-Bustillos RJ, Olsen C, Friedman M, Henika PR, Martín-Belloso O, Pan Z, McHugh TH (2007) Effects of plant essential oils and oil constituents on mechanical, barrier and antimicrobial properties of alginate-apple puree edible films. J Food Eng 81:634-641

8. Reddy KRN, Reddy CS, Muralidharan K (2009) Potential of botanicals and biocontrol agents on growth and aflatoxin production by Aspergillus flavus infecting rice grains. Food Control 20:173-178

9. Zeringue HJ, Bhatnagar D (1990) Inhibition of aflatoxin production in Aspergillus flavus infected cotton bolls after treatment with neem (Azadirachta indica) leaf extracts. J Am Oil Chem Soc 67:215-216

10. Juliano C, Mattana A, Usai M (2000) Composition and in vitro antimicrobial activity of the essential oil of Thymus herba-barona Loisel growing wild in Sardinia. J Essent Oil Res 12:516-522

11. Karaman S, Digrak M, Ravid U, Ilcim A (2001) Antibacterial and antifungal activity of the essential oils of Thymus revolutus Celak from Turkey. J Ethnopharmacol 76:183-186

12. Mahmoud AL (1994) Antifungal action and antiaflatoxigenic properties of some essential oil constituents. Lett Appl Microbiol 19:110-113

13. Wright MS, Greene-McDowelle DM, Zeringue HJ, Bhatnagar D, Cleveland TE (2000) Effects of volatile aldehydes from Aspergillus-resistant varieties of corn on Aspergillus parasiticus growth and aflatoxin biosynthesis. Toxicon 38:1215-1223

14. Philis JG (2005) The S1 $\leftarrow$ S0 spectrum of jet-cooled p-cymene. Spectrochim Acta Mol Biomol Spectrosc 61:1239-1241

15. Marchese A, Arciola CR, Barbieri R, Silva AS, Nabavi SF, TseteghoSokeng AJ, Izadi M, Jafari NJ, Suntar I, Daglia M, Nabavi SM (2017) Update on monoterpenes as antimicrobial agents: a particular focus on p-cymene. Materials 10(8):947

16. Association of Official Analytical Chemist (AOAC) (2000) Chapter 49: official methods analysis. Natural toxins, 17th edn. AOAC International, Gaithersburg 
17. Ok HE, Kim DM, Kim D, Chung SH, Chung MS, Park KH, Chun HS (2014) Mycobiota and natural occurrence of aflatoxin, deoxynivalenol, nivalenol and zearalenone in rice freshly harvested in South Korea. Food Control 37:284-291

18. Wang K, Jiang S, Pu T, Fan L, Su F, Ye M (2018) Antifungal activity of phenolic monoterpenes and structure-related compounds against plant pathogenic fungi. Nat Prod Res 32:1-8

19. Zhang Z, Yang T, Mi N, Wang Y, Li G, Wang L, Xie Y (2016) Antifungal activity of monoterpenes against wood white-rot fungi. Int Biodeter Biodegr 106:157-160

20. Dzhavakhiya VG, Voinova TM, Popletaeva SB, Statsyuk NV, Limantseva LA, Shcherbakova LA (2016) Effect of various constituents blocking the colony pigmentation on the aflatoxin B1 production by Aspergillus flavus. Toxins 8:313

21. Pal AK, Gajjar DU, Vasavada AR (2014) DOPA and DHN pathway orchestrate melanin synthesis in Aspergillus species. Med Mycol 52:10-18

22. Hamada T, Asanagi M, Satozawa T, Araki N, Banba S, Higashimura N, Akase T, Hirase K (2014) Action mechanism of the novel rice blast fungicide tolprocarb distinct from that of conventional melanin biosynthesis inhibitors. J Pestic Sci 39:152-158

23. Cary JW, Harris-Coward PY, Ehrlich KC, Di Mavungu JD, Malysheva SV, De Saeger S, Dowd PF, Shantappa S, Martens
SL, Calvo AM (2014) Functional characterization of a veA-dependent polyketide synthase gene in Aspergillus flavus necessary for the synthesis of asparasone, a sclerotium-specific pigment. Fungal Genet Biol 64:25-35

24. Brown DW, Salvo JJ (1994) Isolation and characterization of sexual spore pigments from Aspergillus nidulans. Appl Environ Microb 60:979-983

25. Abe F, Hiraki T (2009) Mechanistic role of ergosterol in membrane rigidity and cycloheximide resistance in Saccharomyces cerevisiae. BBA Biomembr 1788:743-752

26. Ahmad A, Khan A, Akhtar F, Yousuf S, Xess I, Khan LA, Manzoor N (2011) Fungicidal activity of thymol and carvacrol by disrupting ergosterol biosynthesis and membrane integrity against Candida. Eur J Clin Microbiol 30:41-50

27. Calvo AM, Wilson RA, Bok JW, Keller NP (2002) Relationship between secondary metabolism and fungal development. Microbiol Mol Biol Rev 66:447-459

28. Yoshinari T, Akiyama T, Nakamura K, Kondo T, Takahashi Y, Muraoka Y, Nonomura Y, Nagasawa H, Sakuda S (2007) Dioctatin A is a strong inhibitor of aflatoxin production by Aspergillus parasiticus. Microbiology 153:2774-2780 